$\underline{\text { Research Article }}$

\title{
SAFETY CLIMATE TO PSYCHOLOGICAL WELLBEING ON CIVILIAN PILOT IN INDONESIA
}

\author{
AMILYA AGUSTINA ${ }^{1 *}$, WIDURA I MUSTOPO², BOY S SABARGUNA ${ }^{3}$, GRACE WANGGE ${ }^{4}$ \\ DANARDI SOSROSUMIHARDJO
}

${ }^{1}$ Department of Community Medicine, Faculty of Medicine Universitas Indonesia, Jalan Pegangsaan Timur No.16, Jakarta, Indonesia. ${ }^{2}$ The Saryanto Institute for Medical and Health Aviation and Aerospace (LAKESPRA), Jakarta, Indonesia. ${ }^{3}$ Department of Community Medicine, Faculty of Medicine, Universitas Indonesia, Jakarta, Indonesia. ${ }^{4}$ Southeast Asian Ministers of Education Organization Regional Center for Food and Nutrition (SEAMEO RECFON), Jakarta, Indonesia. ${ }^{5}$ Department of Psychiatry, Faculty of Medicine, Universitas Indonesia, Jakarta, Indonesia. Email: amilyaagustina@ui.ac.id

Received: 3 September 2020, Revised and Accepted: 1 December 20200

\section{ABSTRACT}

Objective: Psychological wellbeing of the pilot can affect the flight cognitive function of the pilot, thus endangering the safety of the flight. The level of wellbeing of the pilots is related to the safety climate of the pilot. The purpose of this study is to determine the relationship between the safety climate and psychological wellbeing of civilian pilot in Indonesia.

Methods: This was an analytic study using cross-sectional method. The sample was determined by consecutive sampling technique. Data were collected by filling out questionnaires by subjects regarding the variables of the safety climate and psychological wellbeing. The data analysis used was multiple linear regression.

Results: The safety climate has a significant effect on psychological wellbeing $(\Omega=0.921)$. The dimensions of the safety climate which have a significant effect are management $(\beta=0.135)$, safety systems $(\beta=0.143)$, procedures $(\beta=0.176)$, training $(\beta=0.153)$, communication $(\beta=0.232)$, and operations personnel $(ß=0.185)$

Conclusion: Management, safety systems, procedures, training, communication, and operations personnel have significant effects on psychological wellbeing of civilian pilot in Indonesia.

Keywords: Safety climate, Psychological wellbeing, Civilian pilot.

\section{INTRODUCTION}

In the world of civil aviation, the most important thing is safety. It is important for aviation community, especially civilian pilots to always have safety attitude during duty. According to the 2010-2016 flight accidents investigation data released by the National Transportation Safety Committee of Indonesia (KNKT), total accidents and serious incidents reached 212 incidents of which the main culprit was human factor of $67.12 \%$ [1]. These data show the importance of studying human factors in terms of improving flight safety.

How a pilot treats himself, for example, his health and wellbeing determine the success and welfare in the future and his readiness on duty [2]. A study conducted by Cottini and Lucifora in Europe showed that workers with better psychological wellbeing were generally more productive, rarely experienced diseases that limited their work capacity and rarely applied for sick leave [3]. Another study by Guindon and Cappeliez showed that psychological wellbeing has a direct effect on subjective health as well as indirect effects on physical health [4].

Psychological wellbeing (PWB) describes wellbeing from an eudemonic perspective. Ryff defines psychological wellbeing as a condition in which individuals have a positive attitude toward themselves and others, can make their own decisions and manage their own behavior, can create and manage environments that are compatible with their needs, have a purpose in life and make their lives more meaningful, as well as trying to explore and develop himself [5].

The influence of psychological wellbeing on health can be seen from negative psychological point of view. Psychological stress arises when a person feels environmental demands beyond their adaptive capabilities. In general, a stressful event affects the pathogenesis of physical illness by causing negative affective states (e.g., feelings of anxiety and depression), which ultimately gives direct effect on biological process or on pattern of behavior that affects disease risk. Behavioral changes arise as adaptations or coping responses, as an example of increased smoking habits, reduced exercise and sleep, and decreased adherence to medical recommendations [6].

Psychological wellbeing itself is part of the human factor in aviation. According to the International Civil Aviation Organization (ICAO) doc 9806 on human factors guidelines for safety manual audits of 2002, humans are the most flexible, adaptable, and valuable element in the aviation system, but also most vulnerable to influences that may affect performance. To explain the various components of the human factor, the SHEL model consists of Software (procedures, symbols, etc.), hardware (machine), environment (situations in which humans, machines, and procedures must function), and Liveware (human) [7].

A study by Ray-Sannerud, Leyshon, and Vallevik showed psychological wellbeing with determinants such as fatigue, psychological distress, and low job satisfaction, leaving workers unprofessional and making mistakes that ultimately increase the number of undesirable events [8]. This suggests that psychological wellbeing is also closely related to safety.

A study by Clarke, 2010, shows that a safety climate affecting health and wellbeing further affects the incidence of occupational accidents [9]. The safety climate itself is generally defined by Zohar, 2011 , as a perception of safety policies, procedures, and practices within an organization [10].

A negative perception of the work environment will lead to a stressful work experience and have the effect of reducing physical and 
psychological health. The perception of a safety climate would predict general health which would predict accidents [9]. One study assess the relationship between the safety climate and psychological wellbeing was conducted by Fogarty, 2004, quoted from Mustopo, 2015, where the results of the study show a significant association between the safety climate and psychological stress as well as a significant relationship between psychological stress and errors in maintenance [11]. Fogarty and Buikstra [12] develop models that illustrate the relationship between occupational safety, occupational psychological health, selfreported errors and violation behavior. The model shows that a safety climate affects psychological health that then affects errors.

The safety climate itself consists of many dimensions and varies in each study. For example, a study of safety climate on pilots conducted by the Australian Transport Safety Bureau (ATSB) in 2004 found that important safety climate dimensions include management commitment, training, equipment and maintenance, and rules and procedures [13] Another study by Gibbons et al., 2006, assesses the safety culture of civil pilots in the United States using safety climate dimensions such as organizational commitment, operations personnel, safety systems, and compliance [14].

Based on the above, the researcher feels the need to study the safety climate and the psychological wellbeing of the civil pilot community, in which the profession is closely related to safety. Thus, the objective of this study is to assess the relationship between the safety climate and psychological wellbeing, as well as to determine a model consists of safety climate's dimensions to achieve psychological wellbeing.

\section{METHODS}

This research is a quantitative research using cross-sectional method. The study population is all civilian pilots who have CPL or ATPL certificate in Indonesia amounted to 8000 people. The samples were taken from that population at the time; they were conducting routine medical examination (Medex) at Civil Aviation Medical Center Indonesia (Balai Kesehatan Penerbangan Indonesia). Number of pilots conducting routine Medex as much as $20-50$ pilots/day or $400-1000 /$ month. The sample is determined by consecutive sampling technique. Data on the safety climate and psychological wellbeing were taken with the questionnaire.

Safety climate is one climate experienced by workers in an organization. Various types of other climates such as customer service climate and innovation climate. According to Schneider, 1990, all of these climate types are based on shared perceptions among workers on practices, procedures, and behavioral types worthy of appreciation and support by organizations and associated with specific strategic focus [15]. When the strategic focus involves the performance of high-risk operations, shared perceptions produce a safety climate [16]. A study was conducted by O'Connor et al., 2011, to find out how to measure the safety climate based on previous studies conducted in the aviation industry. The results of the study showed that from 9 safety climate questionnaires obtained from the literature review, they found 8 dimensions of safety climate which are management/supervision, safety system, procedures/rule, training/education, risk, communication, resources, and operations personnel [17]. Thus, the safety climate dimensions of this study are:

1. Management

This dimension illustrates the importance of the relationship between superiors and workers. Management's participation and involvement in work and safety activities as well as communication between management and workers are important to influence one's perception of management's commitment to safety.

2. Safety system

This dimension describes the reporting system by pilots, the response to such reporting and other factors related to pilots namely accountability, authority, and professionalism toward safety.

3. Procedures

This dimension describes perceptions of safety procedures/rules, compliance with procedures, and treatment of procedural violations.
4. Safety training

This dimension illustrates the pilot's perception of the importance of safety training as well as the qualifications, expertise, and safetyrelated knowledge.

5. Risk

This dimension illustrates the perception of higher threats associated with safety behavior in work and pilot's participation in safety programs.

6. Communication

This dimension illustrates the perceptions of the ongoing communication between workers in the aviation industry. Communication can be a challenge because in its operations the pilot must communicate with other pilots as well as other work groups.

7. Resources

This dimension illustrates the perception of the existence of resources for safety, for example, money, time, equipment, etc.

8. Operation personnel

This dimension describes personnel commitment to safety. Due to the existence of different working groups in the aviation industry, it is important to know the commitment of operating personnel to safety.

Measuring the safety climate at pilots, the researcher used a questionnaire consisting of eight dimensions of safety climate described in 48 items. Items have been validated with the level of validity between 0.283 and 0.802 with a level of reliability of 0.943 .

Ryff expressed psychological wellbeing in a multidimensional model, consisting of six psychological dimensions, namely [18]:

1. Self-acceptance refers to positive feelings toward oneself and his past, although he is aware of the shortcomings he has.

2. Good relations with others refer to developing and maintaining a warm, satisfying, and reliable interpersonal relationship.

3. Environmental mastery involves feeling capable and competent in managing the environment to meet personal needs, desires, and values.

4. Autonomy is defined as a feeling capable of self-determination and against social pressure to think and act in a certain way.

5. Purpose in life refers to the meaning of life and its purpose.

6. Personal growth focuses on self-improvement and self-development and takes advantage of one's talents and capacities to the fullest.

The scale of psychological wellbeing on pilots is measured using Ryff Scale. This questionnaire has been validated with a level of validity between 0.551 and 0.860 and has reliability with Cronbach's alpha of 0.766 . The questionnaire used is Ryff Scale with 18 questions describing the six dimensions of psychological wellbeing. Respondents were asked to state the answer to each question on the lowest scale of 1 if "strongly disagree" to the highest scale of 6 if "strongly agree." The final score is the sum of each scale on each question. The higher the psychological wellbeing scale the better the psychological wellbeing of the respondents.

\section{RESULTS}

Among the 150 questionnaires distributed, there were 137 subjects meeting the criteria for the sample. The subjects were between 19 and 59 years old from the youngest to the oldest, where the most were in the range of 25-69 years with a percentage of $76.64 \%$. All respondents were Asian with CPL license type 59.85\% and ATPL 40.15\%. There were more Co-Pilots than Captain Pilots. Furthermore, based on the total flight hours, most of the pilots have been in flight more than $4,000 \mathrm{~h}$ with a percentage of $40.15 \%$, while there were only $25.55 \%$ of respondents who just make flights $<1000 \mathrm{~h}$. In the past month, most have had flying hours between 51 and $150 \mathrm{~h}$ with the most type of company is Scheduled Commercial.

Table 1 shows that the total score of safety climate and psychological wellbeing each has an average rating of 247.57 and 90.84 . Each dimension of the safety climate has a different minimum value; safety system dimension has the lowest minimum value. The lowest average 
value is in the communication dimension and the highest average value is in the resource dimension.

The data in this research have fulfilled the prerequisite test of multiple linear regression analysis, where the data have normal distribution, free from multicollinearity and heteroscedasticity and fulfill linearity assumption. From the bivariate analysis, significance values were obtained from the interaction of each dimension of the safety climate to psychological wellbeing under 0.25 which means that all dimensions can be analyzed to multivariate. Multivariate analysis results can be seen in the following Table 2 .

Psychological wellbeing prediction $=2.623+0.135$ Good perception of management +0.143 Good perception of safety system +0.176 Good perception of procedure +0.153 Good perception of training +0.232 Good perception of communication +0.135 Good perception of operation personnel.

\section{DISCUSSION}

This study had several limitations, namely there were many factors that can affect psychological wellbeing but not examined because of limitations in terms of tools, technical, and time in this study; the relationship between dimensions of the safety climate variables to other dimensions not examined because researcher focused more on the effect of the overall safety climate dimensions on psychological wellbeing.

From the interaction between safety climate to psychological wellbeing, regression coefficient obtained is 0.921 and $t$ value $=27.542$ with probability $\mathrm{p}<0.001$. Because of $\mathrm{p}<0.05$ hence can be concluded that safety climate variables have significant effect on variable of psychological wellbeing. The regression coefficient obtained is positive value of 0.921 ; it means that there is a directional/positive relationship. As the safety climate increases, psychological wellbeing will increase as well and as the safety climate decreases, pilot's psychological wellbeing will decrease as well. This result is consistent with a study by Clarke in 2010, a metaanalysis study involving 113 studies of climate-related safety, psychological climate, health, wellbeing, etc., shows that a safety climate affects health and wellbeing and then affects the incidence of workplace accidents. This result is also consistent with the literature and study of occupational stress by Kerr, 1957, which was also quoted from Clarke that negative perceptions of the work environment can lead to stress and decreased psychological wellbeing. Thus, a negative safety climate can cause occupational stress and has the effect of decreasing physical and psychological wellbeing. This will make the worker more vulnerable to accidents as it increases the likelihood of making mistakes through cognitive mechanisms such as distraction, decreased attention, and fatigue [9].

From the interaction between management dimension to psychological wellbeing, regression coefficient obtained is 0.135 and $t$ value $=1.991$ with $\mathrm{p}=0.049$. Because of $\mathrm{p}<0.05$ hence can be concluded that dimension of management has positive and significant influence to variable of psychological wellbeing. The value of regression coefficient is positive (0.149) which means that there is a positive influence between management on psychological wellbeing, which with the increasing of safety management will increase the psychological wellbeing of civil pilots in Indonesia. Management dimension illustrates the importance of the relationship between superiors and workers. Participation and management involvement in work and safety activities as well as communication between management and workers is important to influence one's perception of management's commitment to safety. This result is in accordance with a study conducted by Chen et al. in 2017 toward construction workers in Ontario. The aim of this study was to produce a model which shows that the safety climate has an indirect effect on psychological stress through unsafe events, where the dimension that most describes the safety climate is the management commitment to safety [19]. With the management's involvement in safety provides a sense of security and comfort to the pilots in doing their work. Pilots believe management will prioritize safety and respond quickly to safety issues. This is one of the forms of social support which is one of the factors affecting psychological wellbeing [20].

In the interaction between the safety system dimension to the psychological wellbeing variable, regression coefficient obtained is 0.143 and $t$ value $=2.075$ with $p=0.040$. Because of $p<0.05$ hence can be concluded that safety system dimension has positive and significant influence to variable of psychological wellbeing. The value of the regression coefficient is positive $(0.143)$ which means that there is a positive influence between the safety systems to the psychological wellbeing, which with the increasing safety system will increase the psychological wellbeing of civil pilots in Indonesia. The safety system dimension describes the reporting system by the pilot, the response to the reporting and other factors related to the pilot. These results are in line with studies conducted by the Chartered Institute of Personnel

Table 1: Descriptive statistic

\begin{tabular}{|c|c|c|c|c|c|}
\hline & $\mathbf{n}$ & Minimum & Maximum & Mean & Standard deviation \\
\hline Psychological wellbeing & 137 & 70 & 106 & 90.84 & 9.495 \\
\hline Safety climate & 137 & 194 & 285 & 247.57 & 23.741 \\
\hline Management & 137 & 21 & 36 & 30.43 & 3.753 \\
\hline Safety system & 137 & 20 & 36 & 30.53 & 3.527 \\
\hline Procedure & 137 & 23 & 36 & 31.28 & 3.545 \\
\hline Training & 137 & 24 & 36 & 31.34 & 3.366 \\
\hline Risk & 137 & 25 & 36 & 31.28 & 2.852 \\
\hline Resource & 137 & 24 & 36 & 31.45 & 3.240 \\
\hline Operation personnel & 137 & 24 & 36 & 31.42 & 3.175 \\
\hline
\end{tabular}

Table 2: Multivariate analysis result

\begin{tabular}{lllll}
\hline Independent variable & Constant $^{\mathbf{a}}$ & Beta & t & Description \\
\hline Good perception of management & 2.623 & 0.135 & 1.991 & 0.049 \\
Good perception of safety system & & 0.143 & 2.075 & 0.040 \\
Good perception of procedure & & 0.176 & 2.395 & 0.018 \\
Good perception of training & & 0.153 & 2.126 & 3.778 \\
Good perception of communication & & 0.232 & $<.035$ \\
Good perception of operation personnel & 0.135 & Significant & 1.991 \\
\hline
\end{tabular}

F value $=130.507$ and $p \leq 0.001 . R^{2}=0.858$ 
and Development (CIPD) year 2016, which shows that a good reporting system between employers and workers is one of the things that can improve workers' wellbeing [21]. A good safety system is that management responds quickly to reports of safety problems and that pilots can report without fear of any negative impact on them. This illustrates one dimension of psychological wellbeing: Autonomy in which one feels independent and able to overcome the social pressure to think and act in a certain way [5]

In the interaction between the procedure dimension to psychological wellbeing variable, regression coefficient obtained is 0.176 and $t$ value $=2.396$ with $p=0.018$. Because of $p<0.05$ hence can be concluded that procedure dimension has positive and significant effect to variable of psychological wellbeing. The value of the regression coefficient is positive (0.176) which means that there is a positive influence between the safety procedures on psychological wellbeing, which with the increasing safety procedures will increase the psychological wellbeing of civil pilots in Indonesia. The dimensions of safety procedures illustrate perceptions of safety procedures/rules, compliance with procedures, and treatment of procedural violations. These results are in accordance with a 2005 study by Mearns and Hope toward offshore workers who showed that following procedures is a part of the healthy behavior index. Compliance with safety procedures also reduces accident rates and injuries [22].

In the interaction between training dimension to psychological wellbeing variable, regression coefficient obtained is 0.153 and $t$ value $=2.126$ with $p$ value of 0.035 . Because of $p<0.05$ hence can

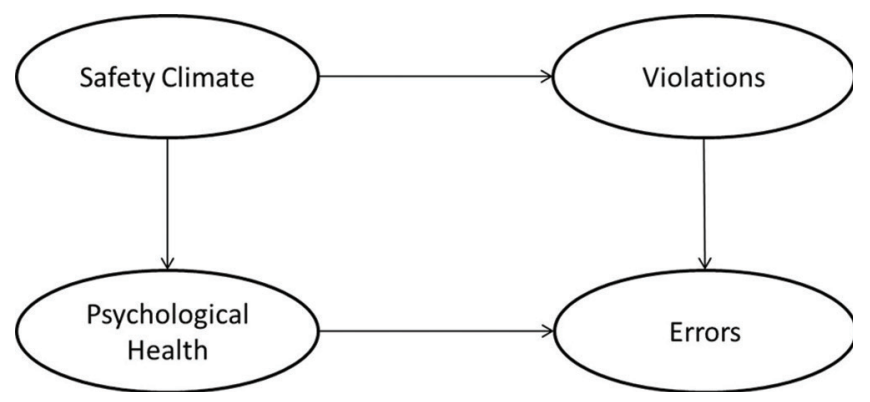

Fig. 1: Relationship model of safety climate, psychological health, errors, and violations

Source: Fogarty G, Buikstra E (2008) [12] be concluded that training dimension has positive and significant influence to variable of psychological wellbeing. The value of the regression coefficient is positive $(0.163)$ which means that there is a positive influence between the safety training on psychological wellbeing, which with the increasing of safety training will increase the psychological wellbeing of civil pilots in Indonesia. The training dimension illustrates the pilot's perception of the importance of safety training as well as the qualifications, expertise, and safety related knowledge. This result is in accordance with research conducted by Sprutza et al. to know the effect of Metal Age training program on workers' wellbeing; this study was conducted on 636 workers from 13 companies in Latvia. Metal Age training is a training to develop wellbeing in the work environment by increasing profitability and productivity within the organization. This study shows that after intervention with training, the wellbeing of workers increases [23]. Another study conducted by Chartered Institute of Personnel and Development (CIPD), London, a professional organization for Human Resources development and people, issued a wellbeing model consisting of 5 domains: Health, work, personal growth, values, and social. In each domain, there are elements in which there are various training as part of the model to improve workers' wellbeing. One example of the health domain of physical and mental health element, to improve the wellbeing of workers is by doing personal safety training and conflict resolution training, while from the self-growth domain of emotional element, there is personal resilience training [21].

In interaction between communication dimension to psychological wellbeing variable, regression coefficient obtained is 0.232 and $t$ value $=3.778$ with $p<0.001$. Because of $p<0.05$ hence can be concluded that dimension of communication has positive and significant influence to variable of psychological wellbeing. The value of regression coefficient is positive $(0.232)$ which means that there is positive influence between communications to psychological wellbeing, which with the increasing of communication of safety hence will increase the psychological wellbeing of civil pilots in Indonesia. The dimension of communication illustrates the perception of ongoing communication between workers in the aviation industry. This result is in line with study conducted by the Health, Safety and Wellbeing Committee, University of Glasgow, which says that poor communication is one of the causes of psychological stress in the workplace [24]. Another study conducted by Akerboom and Maes in 2006 studied the job-demand-control model as a determinant

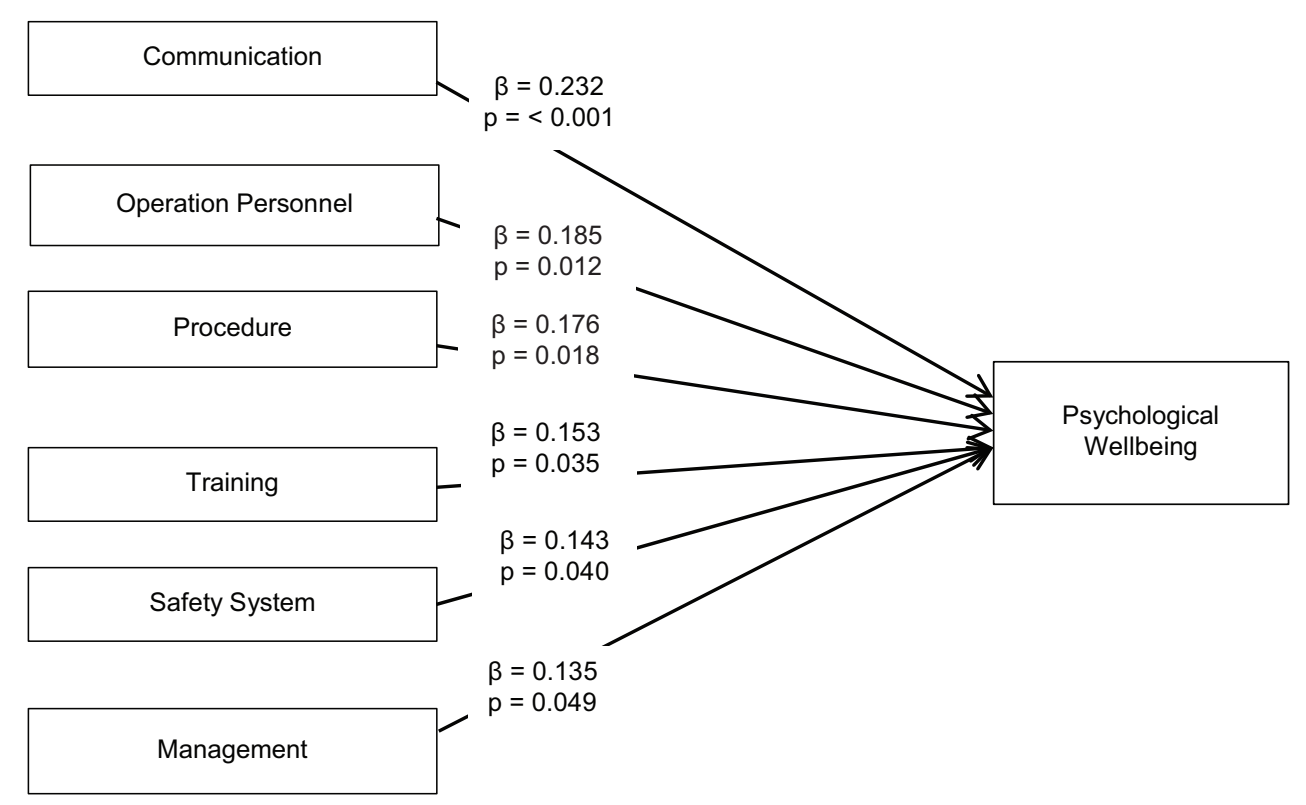

Fig. 2: Model design 
of the psychological wellbeing of workers. This study shows that communication and training have a significant relationship with job satisfaction. The better and smoother the communication between workers, workers with superiors, and also between departments, then the more increasing job satisfaction [25]. Communication can be a challenge because in its operations the pilot must communicate with other pilots as well as other working groups such as air traffic controllers, maintenance personnel, cabin crew, and dispatch or departure division.

In the interaction between the personnel operation dimension to psychological wellbeing variable, regression coefficient obtained is 0.185 and $t$ value $=2.538$ with $p=0.012$. Because of $p<0.05$ hence it can be concluded that the dimension of operation personnel has positive and significant effect to psychological wellbeing variable. The value of regression coefficient is positive $(0.185)$, which means that there is positive influence between operation personnel to psychological wellbeing, which with increasing of commitment of operation personnel to safety will increase psychological wellbeing of civil pilots in Indonesia. The dimensions of operating personnel describe personnel commitment to safety. Due to the existence of different working groups in the aviation industry, it is important to know the commitment of operating personnel to safety. A plane crash can occur due to many factors, including the factor of the plane itself, the human error factor, the weather factor, or even malfunction of the airport facilities, so that every element of the flight operation has a contribution to safety [26].

The results of this research indicate that from 8 dimensions of safety climate used in this research, there is 6 dimensions which has significant effect to psychological wellbeing, namely, management, safety system, safety procedure, safety training, communication, and operation personnel. While there are two dimensions of the safety climate that has no significant effect on psychological wellbeing that is the dimension of risk and resources. Model that can be made based on the results of this study are:

\section{CONCLUSION}

As a conclusion, management, safety system, safety procedure, safety training, communication, and operation personnel have been shown to have an effect on the psychological wellbeing of civil pilots in Indonesia, while risks and resources have not been shown to affect the psychological wellbeing of civil pilots in Indonesia. The overall safety climate affects the psychological wellbeing of civil pilots in Indonesia. The most dominant dimension of safety climate that affects the psychological wellbeing is communication dimension.

From the results of this study, we can make several recommendations. For the pilots to raise awareness of the importance of psychological wellbeing as part of mental health which is closely related to the incident / accident event in flight. Pilots also to improve flight safety awareness by complying with procedures and reporting events that endanger the safety of aviation.

For airlines to perform prevention before accident by assessing the psychological wellbeing of pilots by measuring the safety climate dimensions that have been included in the model design. Airlines are also expected to strengthen the organizational structure in the field of operations that are directly related to aviation safety, for example by establishing a special unit of director level so that the safety policy becomes a priority. Other than that airlines need to strengthen and oversee the implementation of aviation safety reporting guidance in all aspects of aviation operations and be able to convey the latest safety procedures through regular socialization and improve supervision of operational personnel training activities. The need for good airline management support in providing support and listening to pilot input or problems. It is expected to create a comfortable working environment for pilots to improve good communication.
For the next researcher, it is expected to examine the relationship of each dimension of the safety climate and the dimensions of the psychological wellbeing variable and does research by detecting the contribution of demographic factors and environmental factors to the pilot's psychological wellbeing.

\section{REFERENCES}

1. Komite Nasional Keselamatan Transportasi. Data Investigasi Kecelakaan Penerbangan 2010-2016 (Aviation Accident Investigation Data 20102016). Jakarta: Komite Nasional Keselamatan Transportasi; 2016.

2. Chaturvedula S, Joseph C. Dimensions of psychological well-being and personality in military aircrew: A preliminary study. IJASM 2007;51:17-27.

3. Guindon S, Cappeliez P. Contributions of psychological well-being and social support to an integrative model of subjective health in later adulthood. Ageing Int 2010;35:38-60.

4. Cottini E, Lucifora C. Working Conditions, Mental Health and Psychological Well-being in European Countries. Germany|: IZA Discussion Paper; 2010. p. 4717.

5. Ryff CD. Happiness is everything, or is it? explorations on the meaning of psychological well-being. J Personality Soc Psychol 1989;57:1069-81.

6. Cohen S, Janicki-Deverts D, Miller GE. Psychological stress and disease. JAMA 2007;298:1685-7.

7. ICAO. Doc 9806 Human Factors Guidelines for Safety Audits Manual. $1^{\text {st }}$ ed. Canada: ICAO; 2002.

8. Ray-Sannerud BN, Leyshon S, Vallevik VB. Introducing routine measurement of healthcare worker's well-being as a leading indicator for proactive safety management systems based on resilience engineering. Proc Manuf 2015;3:319-26.

9. Clarke S. An integrative model of safety climate: Linking psychological climate and work attitudes to individual safety outcomes using metaanalysis. J Occup Organ Psychol 2010;83:553-78.

10. Griffin MA, Curcuto M. Safety climate in organizations: New challenges and frontiers for theory, research and practice. Ann Rev Organ Psychol Organ Behav 2016;3:191-212.

11. Mustopo WI. The Influence of Psychological Wellbeing and Aviation Safety Climate on Pilot's Unsafe Actions in the form of Flight Violations and Incidents, Disertation. Indonesia: Universitas Indonesia; 2015.

12. Fogarty G, Buikstra E. A test of direct and indirect pathways linking safety climate, psychological health, and unsafe behaviours. Int J Appl Aviat Stud 2008;8:199-210.

13. Australian Transportation Safety Board. ATSB Aviation Safety Surveysafety Climate Factors. Canberra, Australia: Australian Transportation Safety Board; 2004.

14. Gibbons AM, von Thaden TL, Wiegmann DA. Development and initial validation of a survey for assessing safety culture within commercial flight operations. Int J Aviat Psychol 2006;16:215-38.

15. Griffin MA, Neal A. Perceptions of safety at work: A framework for linking safety climate to safety performance, knowledge, and motivation. J Occup Health Psychol 2000;5:347-58.

16. Zohar D. Thirty years of safety climate research: Reflections and future directions. Accid Anal Prev 2010;42:1517-22.

17. O'connor P, O'Dea A, Kennedy Q, Buttrey SE. Measuring safety climate in aviation: A review and recommendations for the future. Saf Sci 2011;49:128-38

18. Lee HE, Taniguchi E. A Cross-cultural Validation of the Six-factor Model of Psychological Well-being. Available from: http://www. congress.aks.ac.kr/korean/files/2_1413778533.pdf. [Last accessed on $2017 \mathrm{Feb} 18]$.

19. Chen Y, McCabe B, Hyatt D. Impact of individual resilience and safety climate on safety performance and psychological stress of construction workers: A case study of the Ontario construction industry. J Saf Res 2017;61:167-76.

20. Lakoy FS. Psychological well-being perempuan bekerja dengan status menikah dan belum menikah (psychological well-being married and unmarried women). J Psikol 2009;7:38-47.

21. Chartered Institute of Personnel and Development. Growing the Health and Well-being Agenda: From First Steps to Full Potential; 2016. Available from: https://www.cipd.co.uk/Images/health-wellbeing-agenda_2016-first-steps-full-potential_tcm18-10453.pdf. [Last accessed on 2017 Jun 26].

22. Mearns K, Hope L. Health and Well-being in the Offshore Environment: The Management of Personal Health. Health and Safety Executive; 2005. Available from: http://www.hse.gov.uk/research/rrpdf/rr305.pdf. [Last accessed on 2017 Jun 26]. 
23. Sprûdza D, Kozlova L, Lakisa S, Mârtiòsone I, Vanadzins I, Baíe MA et al. The impact of metal age $\AA$ training programme on the well-being of latvian office workers. Proc Latv Acad Sci 2016;70:315-24.

24. Health, Safety and Wellbeing Committee. Policy for Managing Stress and Mental Wellbeing in the Workplace. University of Glasgow; 2010. Available from: http://www.gla.ac.uk/media/media 178812 en.pdf.
[Last accessed on 2017 Jun 26].

25. Akerboom S, Maes S. Beyond demand and control: The contribution of organizational risk factors in assessing the psychological well-being of health care employees. Work Stress 2006;20:21-36.

26. Sisilia Y. Implementation of safety management systems as a safety standard for air traffic services. J Ilmu Admin Organ 2009;16:140-6. 